Abstracted/indexed in Academic Search Complete, Asia Journals Online, Bangladesh Journals Online, Biological Abstracts, BIOSIS Previews, CAB Abstracts, Current Abstracts, Directory of Open Access Journals, EMBASE/Excerpta Medica, Google Scholar, HINARI (WHO), International

\title{
Daucosterol inhibits colon cancer growth by inducing apoptosis, inhibiting cell migration and invasion and targeting caspase signalling pathway
}

\author{
Gui-Qi Wang, Jing-Feng Gu, Ying-Chao Gao and Yong-Jun Dai
}

Department of Gastrointestinal Surgery, First Affiliated Hospital of Hebei Medical University, Shijiazhuang, Hebei 050 031, China.

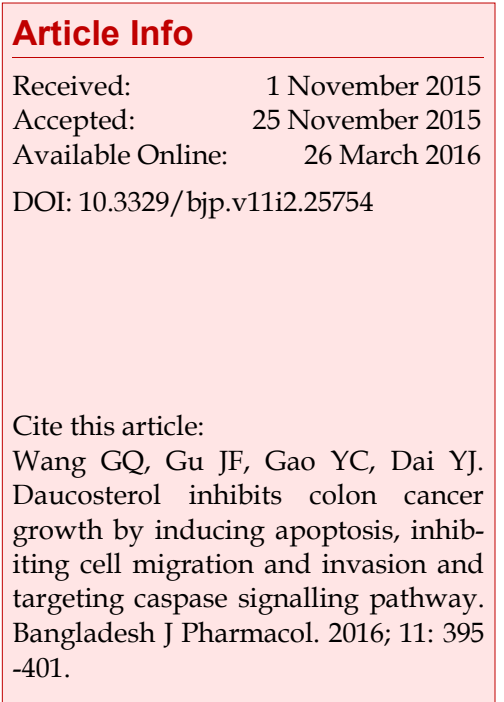

\begin{abstract}
The aim of the present investigation was to examine and demonstrate in detail the anti-cancer and apoptotic effects of daucosterol in human colon cancer cell line HCT-116. The effects of this compound on cell migration, cell invasion, cell cycle analysis and caspase signalling pathway were also studied. Cell viability was evaluated by MTT assay using different doses of the drug. In vitro wound healing assay was used to study cell migration. Flow cytometry was involved to examine cell apoptosis as well as cell cycle phase distribution. Daucosterol induced significant, dose-dependent as well as timedependent cytotoxic effects with $\mathrm{IC}_{50}$ values of 26.6 and $47.3 \mu \mathrm{M}$ at 24 and 48 hours time intervals respectively. The percent of cells that migrated decreased from $99 \%$ in case of untreated control to $84.2,45.2,39.5$ and $14.4 \%$ in groups treated with $0,5,50,75$ and $100 \mu \mathrm{M}$ of daucosterol respectively. Percentage of apoptotic cells increased from $2.5 \%$ in untreated control cells to $23.6,46.9$ and $74.2 \%$ in cells treated with 5,50 and $100 \mu \mathrm{M}$ dose of daucosterol respectively. Daucosterol at different doses induced cell cycle arrest at sub-G1 phase of the cell cycle.
\end{abstract}

\section{Introduction}

Colon cancer is presently one of the most deadly and is ranked third most common malignancy throughout the globe (Ferlay et al., 2010). Most of the colon cancer patients $(20-30 \%)$ at the time of diagnosis have already reached metastases.

The treatment regimen for colon cancer is mainly focused on being palliative rather than curative. The objective of the cancer therapy is to improve patient's life quality and to prolong survival. In a small fraction of the patients with this disease, colon cancer can be made potentially curable through the involvement of surgery coupled with chemotherapy (Van Cutsem and Oliveira, 2009; Folprecht et al., 2005).
Chemotherapeutic treatment of colon cancer includes a number of anticancer drugs like irinotecan, oxaliplatin, 5-fluorouracil, bevacizumab, capecitabine etc. In addition to single drug therapy, a combination therapy of these drugs like oxaliplatin and capecitabine, 5-FU, leucovorin, and oxaliplatin and 5-FU, leucovorin and irinotecan has also been found to improve patient outcomes in many cases (de Gramont et al., 2000; Saltz et al., 2008; Douillard et al., 2010). Despite recent advances in chemotherapeutic treatment, there are numerous serious adverse effects associated with this treatment regimen coupled with the multidrug resistant colon cancer cells.

In current scenario need of an hour is to design and develop novel, less toxic and natural product based 
anticancer drugs which can even target drug resistant cancer cells. Among the drugs that are being used clinically worldwide, $50 \%$ of them are either natural products or their derivatives. The purpose of current was to evaluate the anti-tumor effects of daucosterol in human colon cancer cell line HCT-116. The effect of this compound on caspase signalling pathway as well as on cell migration, cell invasion, cell cycle analysis and cell apoptosis were also examined.

\section{Materials and Methods}

Daucosterol, 3-[4, 5-dimethylthiazol-2-yl]-2, 5-diphenyltetrazolium bromide (MTT), streptomycin/penicillin solution, propidium iodide, and ethanol were purchased from Sigma Chemicals (Sigma-Aldrich, Shanghai). Daucosterol was dissolved in DMSO $(0.5 \%, \mathrm{v} / \mathrm{v})$ in all experiments. PVDF membrane was purchased from Bio -Rad (CA, USA). Monoclonal antibodies to Cytochrome c, Bcl-2, Caspase-3, Bax, Caspase-9, and NF-kB were procured from (Santa Cruz, CA, USA). RPMI-1640 medium and fetal bovine serum (FBS)-heat-inactivated were obtained from Gibco (Carlsbad, USA). DNA Flow Cytometric Analysis Kit and FITC Annexin V Apoptosis Detection Kit were purchased from KeyGEN, Nanjing, China.

\section{Cell lines, culture conditions and cell viability assay using MTT}

Human colon cancer cell line HCT-116 (colon) was procured from Chinese Academy of Medical Sciences Tumor Cell Center (China). Cells were grown in RPMI1640 medium supplemented with $10 \%$ fetal bovine serum and $100 \mathrm{U} / \mathrm{mL}$ penicillin and $100 \mu \mathrm{g} / \mathrm{mL}$ streptomycin. Cell cultures were maintained in a humidified atmosphere with $5 \% \mathrm{CO}_{2}$ at $37^{\circ} \mathrm{C}$. The cell viability of HCT-116 colon cancer cells was determined by MTT assay. The seeding density of $2 \times 10^{5}$ cells per well was maintained and the cells were transferred to 96-well plates for 24 hours incubation. The cells were then subjected to various daucosterol doses $(0,5,10,25$, 50, 75 and $100 \mu \mathrm{M}$ ) for 24 and 48 hours. Following incubation, $10 \mu \mathrm{L}$ of the MTT dye was added. The plate was incubated for 3 hours in a humidified atmosphere. Then $200 \mu \mathrm{L}$ of the DMSO solution was added into each well. Absorbance of the samples was measured spectrophotometrically using an ELISA microplate reader at a wavelength of $570 \mathrm{~nm}$. A solution of RPMI1640 medium (assay medium) acted as negative control. Paclitaxel at a dose of $5 \mu \mathrm{M}$ served as a positive control.

\section{Cell migration assay (Video Clip)}

The human colon cancer cells (HCT-116) were taken in a sterile 12-well plate and horizontal lines were drawn on the base of the plate by keeping it upside down. Then $2 \mathrm{~mL}$ of cell culture containing media was transferred into each well present in this 12-well plate. The plate was covered by the lid and then kept in $\mathrm{CO}_{2}$ incubator for 48 hours at $37^{\circ} \mathrm{C}$. Then the plate was taken out from the $\mathrm{CO}_{2}$ incubator and a scratch in each well was made using a $100 \mu \mathrm{L}$ micropipette tip from the tip box. Then the plate was subjected to different doses of the drug and was then incubated for 48 hours. After incubation the cells were fixed which was followed by staining with $1.5 \%$ crystal violet powder containing $5.5 \%$ ethanol for $20 \mathrm{~min}$. Then using a phase microscope (Olympus, Japan), randomly selected fields were chosen and photographed. Image J software (1.46 version) was used to determine the length of the wounds.

\section{Cell invasion assay}

It was carried out in a 24 -well chamber $(6 \mathrm{~mm}$ pore size) having $20 \mu \mathrm{L}$ Matrigel coating. HCT-116 human colon cancer cells $\left(2 \times 10^{5}\right)$ preincubated with $(0,5,50$, 75 and $100 \mu \mathrm{M}$ ) of daucosterol were seeded in the upper chamber of wells while as chemoattractant was placed in the bottom chambers. The medium $(1.0 \mathrm{~mL})$ containing $10 \%$ FBS was added to the lower compartment of the invasion chamber. After incubation for 48 hours, the filter was fixed and then stained with $1.5 \%$ crystal violet powder containing $5.5 \%$ ethanol for $30 \mathrm{~min}$. Then these cells were counted under light microscope. Data analysis represents mean \pm standard error from three individual experiments in triplicate.

\section{Annexin V-FITC assay for apoptosis}

Annexin V-FITC assay was used to quantify the extent of apoptosis induced by daucosterol in HCT-116 human colon cancer cells by (annexin V-FITC apoptosis detection kit). In short, HCT-116 cells at a density of $2 \mathrm{x}$ $10^{5}$ cells $/ \mathrm{mL}$ were seeded and then exposed to the treatment of daucosterol at various doses $(0,5,50$ and $100 \mu \mathrm{M})$. After this the cells were incubated for 48 hours, washed with PBS and then stained with propidium iodide and annexin V-FITC as per manufacturer instructions. Finally the analysis was done by flow cytometry using FACS Calibur instru-ment with Cell Quest 3.3 software (BD Biosciences, USA)

\section{Cell cycle analysis by flow cytometry}

Effects of daucosterol on the cell cycle phases were examined by flow cytometry using propidium iodide as a probe. HCT-116 human colon cancer cells at a density of $2 \times 10^{5}$ cells $/ \mathrm{mL}$ were plated in a 6 -well plate. The cells were treated with daucosterol at various doses $(0$, $5,50$ and $100 \mu \mathrm{M})$ and incubated at $37^{\circ} \mathrm{C}$ with $5 \% \mathrm{CO}_{2}$ for 48 hours. The cells were harvested and washed with PBS twice and then fixed in cold ethanol at $4^{\circ} \mathrm{C}$ overnight. The cells were then stained with propidium iodide solution containing $0.05 \%$ Triton X-100 and 30 $\mathrm{mg} / \mathrm{mL}$ RNase for $20 \mathrm{~min}$ in dark and then analyzed by 
flow cytometry.

\section{Western blot analysis}

After HCT-116 human colon cancer cells were treated with different doses of daucosterol, the total proteins were extracted with RIPA lysis buffer containing 1\% cocktail and $1 \%$ phenylmethane sulfonylfluoride (PMSF). Protein estimation was done by BCA Protein Assay Kit (Thermo Scientific). The protein lysates (10 $\mu \mathrm{g} /$ lane) were resolved by $10 \%$ SDS-PAGE and transferred onto polyvinylidene difluoride membranes (Millipore, USA). Blocking was done with 6\% skimmed milk, and then membrane was incubated with the desired primary antibodies for caspase-3, anti-cleaved caspase-9, anti-cytochrome c, anti-Bax, anti-Bcl-2 overnight at $4^{\circ} \mathrm{C}$. Subsequently, the membrane was incubated with the secondary antibodies (HRPconjugated goat anti-rabbit or goat anti-mouse IgG) for 1 hour at RT. After incubation the membrane was washed and finally visualized by using an ECL Plus Chemiluminescence kit (Applygen Technologies Inc., China).

\section{Statistical analysis}

The results were represented as mean \pm standard error

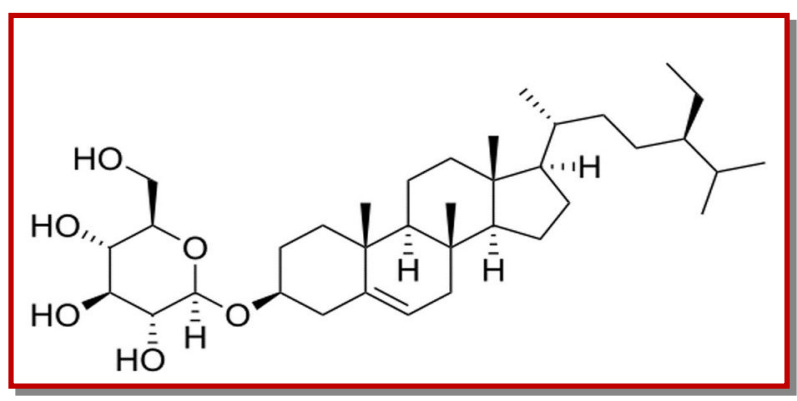

Figure 1: Chemical structure of daucosterol
(S.E.) from three independent experiments. The differences between groups were analyzed by one-way ANOVA, significance of difference was designated as $\mathrm{p}<0.05, \mathrm{p}<0.01$.

\section{Results}

\section{Antitumor activity of daucosterol in HCT-116 human colon carcinoma cells}

The chemical structure of daucosterol is shown in Figure 1. The antitumor effect of daucosterol in HCT116 human colon carcinoma cells is shown in Figure 2. It shows that daucosterol induced significant, cytotoxic effects in a dose dependent as well as time-dependent fashion. The $\mathrm{IC}_{50}$ values at these two times intervals were found to be 26.6 and $47.3 \mu \mathrm{M}$ at 24 and 48 hours time intervals respectively. The cytotoxic effect of daucosterol was compared with a well-known anticancer drug known as paclitaxel which served as positive control. It was found that daucosterol induced similar cytotoxic effect as that produced by $5 \mu \mathrm{M}$ dose of paclitaxel.

\section{Daucosterol inhibits cancer cell migration and invasion in HCT-116 cells}

we have examined the effects of daucosterol on the migration tendency in HCT-116 cells. Migration percentage was calculated as the number of cell migrated towards the scraped area. Figure 3 shows the effect of daucosterol in HCT-116 cells indicating that this compound inhibited cell migration in a dosedependent manner. The percent of cells that migrated decreased from $99 \%$ in case of untreated control to $84.2 \%, 45.2 \%, 39.5 \%$ and $14.4 \%$ in groups treated with 0 , $5,50,75$ and $100 \mu \mathrm{M}$ of daucosterol respectively. Similar results were observed in cell invasion assay which

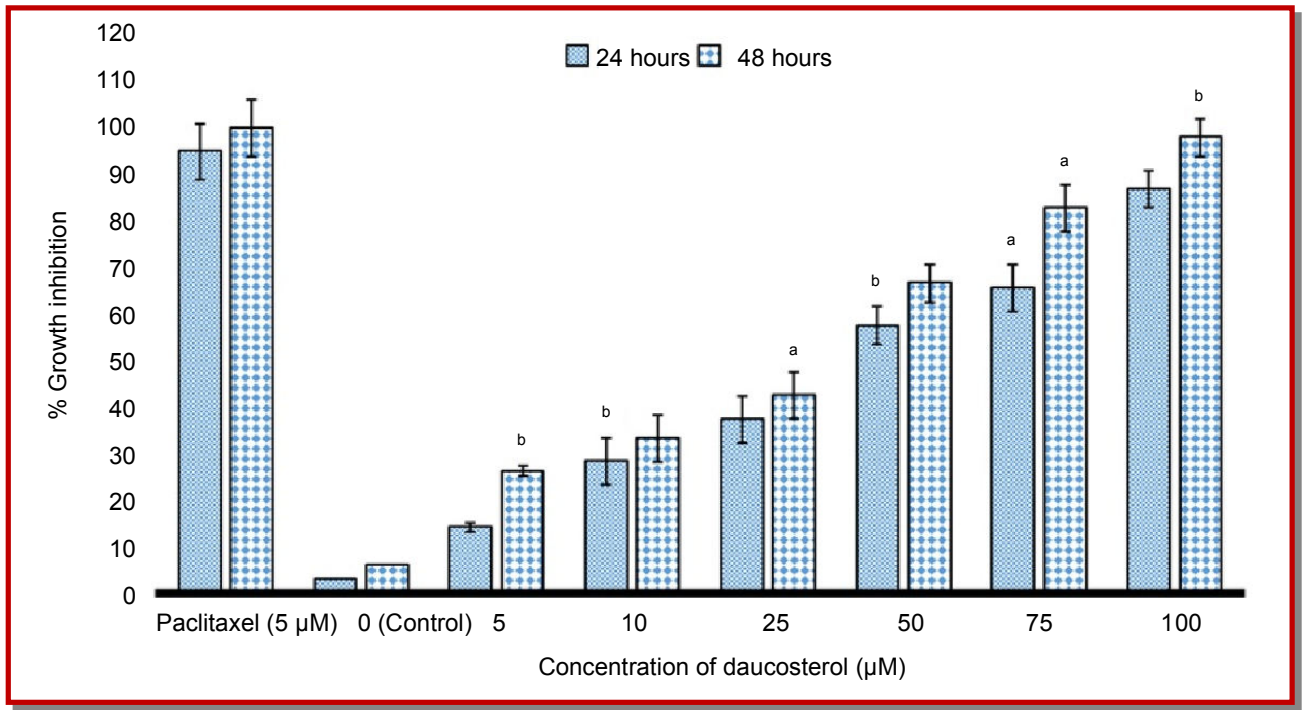

Figure 2: Cytotoxic effect of daucosterol in human colon cancer cells (HCT-116) at different doses. Data are shown as the mean \pm $\mathrm{SD}$ of three independent experiments; a $<<0.05$, b $\mathrm{p}<0.01$, vs $0 \mu \mathrm{M}$ (control) 
revealed that daucosterol inhibited HCT-116 cancer cell invasion in a dose-dependent manner. The percent of cell invasion decreased from $99 \%$ in untreated cells to $95.2,67,34.5$ and $18.7 \%$ in groups treated with $0,5,50$, 75 and $100 \mu \mathrm{M}$ of daucosterol respectively (Figure 4).

\section{Daucosterol induces early and late apoptosis in HCT- 116 colon cancer cells}

In order to demonstrate whether the anti-cancer effects of daucosterol in HCT-116 cells are mediated via apoptosis, flow cytometry was involved using annexin V-FITC and propidium iodide apoptosis kit. Annexin V staining detects phosphatidyl serine and can be used for its study. After cells are stained with annexin $\mathrm{V}$ together with propidium iodide, this reagent enters the cell only when the plasma cell membrane is damaged. The results of this assay reveal the increase in apoptotic cells from $2.45 \%$ in untreated control cells to 23.6, 46.9 and $74.2 \%$ in cells treated with 5,50 and $100 \mu \mathrm{M}$ dose of daucosterol respectively (Figure 5). This includes both the early and late apoptotic cells. Percentage of necrotic, late apoptotic, viable and early apoptotic cells are represented as Q1, Q2, Q3 and Q4 respectively.

\section{Daucosterol induces sub-G1 cell cycle arrest}

The effect of daucosterol on the cell cycle arrest in HCT116 is shown in Figure 6 and indicate that daucosterol at different doses (A-0 $\mu \mathrm{M}, \mathrm{B}-5 \mu \mathrm{M}, \mathrm{C}-50 \mu \mathrm{M}$ and D$100 \mu \mathrm{M}$ ) led to the increase of sub-G1 cells from $3.32 \%$ (control) to $13.3,27.3$ and $49.8 \%$ respectively. This was

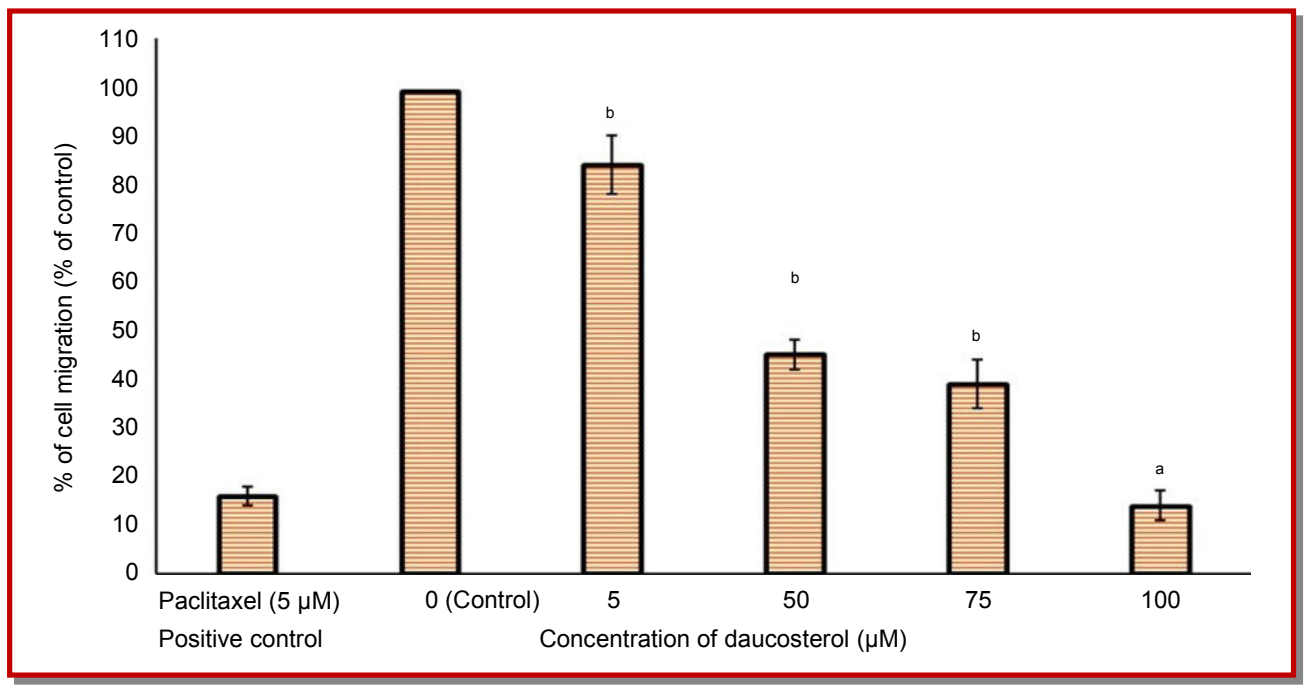

Figure 3: Daucosterol inhibits cell migration ability in HCT-116 colon cancer cells in a dose-dependent manner. Paclitaxel at a dose of $5 \mu \mathrm{M}$ was used as a positive control. Data are shown as the mean \pm SD of three independent experiments. ap $<0.05$, ${ }^{\mathrm{b}} \mathrm{p}<0.01$, vs $0 \mu \mathrm{M}$ (control)

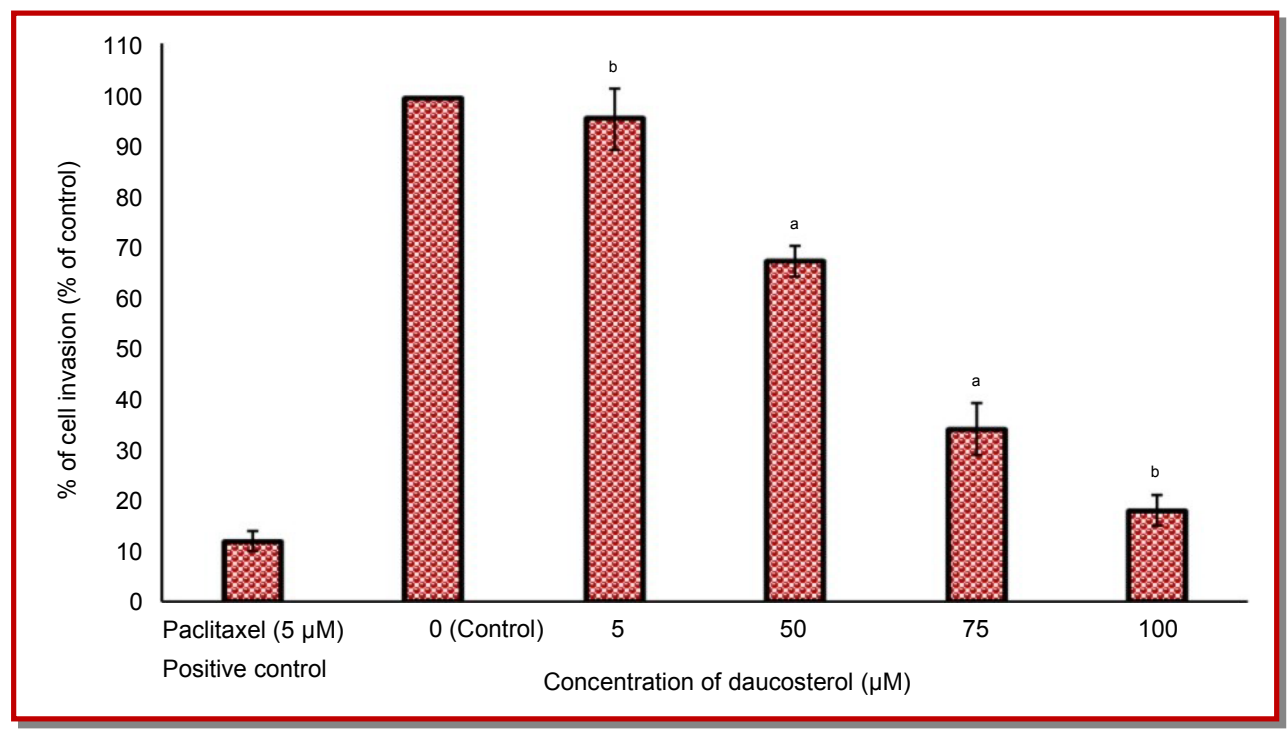

Figure 4: Daucosterol inhibits cell invasion ability in HCT-116 colon cancer cells. Paclitaxel at a dose of $5 \mu \mathrm{M}$ was used as a positive control. Data are shown as the mean \pm SD of three independent experiments. ${ }^{a} p<0.05,{ }^{b} p<0.01$, vs $0 \mu \mathrm{M}$ (control) 
accompanied by a decrease in the $\mathrm{G}_{0} / \mathrm{G}_{1}$ cells from $65.4 \%$ in control to $34.2,33.5$ and $31.6 \%$ respectively in cells treated with 5, 50 and $100 \mu \mathrm{M}$ dose of daucosterol respectively. The cytotoxic effect of the daucosterol causes HCT-116 cells to enter the sub-G1 phase of the cell cycle which is also called as the apoptotic phase (Figure 6).

Effect of daucosterol on the expression levels of cytochrome c, caspase 3, caspase 9, Bax and Bcl-2

Percentage of fold change in the basal expression of caspase-3, 9, cytochrome c, Bax and Bcl-2 due to daucosterol were determined by Western blotting. The results revealed that the expression levels of Bcl-2 got decreased while as the expression levels of Bax, cytochrome c, caspase 3 and caspase 9 increased after treatment with 50 and $100 \mu \mathrm{M}$ concentrations of daucosterol (Figure 7). Bcl-2 protein family plays crucial role in apoptosis, one among them is anti-apoptotic (Bcl-2) while as another one is pro-apoptotic (Bax) . $\mathrm{Bcl}-2$ and Bax also plays key roles via mitochondrial pathway, the Bcl-2 down-regulation and Baxup-regulation contributes towards cytochrome-C release from mitochondria, which in turn triggers caspase cascade by activating caspase- 3 and caspase- 9 which ultimately causes cell apoptosis.

\section{Discussion}

The current study demonstrated in detail apoptotic and anti-cancer potential of daucosterol in human colon cancer HCT-116 cells. It was observed that daucosterol induced potent anticancer effects in these cancer cells through the induction of caspase-mediated apoptosis. Initially we examined the cytotoxic effects of this compound by MTT assay which indicated that daucosterol induced significant cytotoxicity with $\mathrm{IC}_{50}$ values of 26.6 and $47.3 \mu \mathrm{M}$ at 24 and 48 hours time intervals respectively. Further since cell migration and cell invasion are two key parameters of cancerous cells, it was seen in the present study that daucosterol is a potent inhibitor of cell migration and cell invasion indicating its ability to restrict cancer cells within a specified range. Invasion of cancer cells into neighboring tissue and the vasculature is a primary step in tumor metastasis. Cancer cells have a broad variety of migration and invasion mechanisms. These comprise both individual and combined cell-migration approaches (Friedl and Wolf, 2003; Yamaguchi et al., 2005). Apoptotic percentage of cells increased from $2.5 \%$ in untreated control cells to $23.6,46.9$ and $74.2 \%$ in cells treated with 5,50 and $100 \mu \mathrm{M}$ concentrations of daucosterol respectively. This includes both the early and late apoptotic cells. The cytotoxic effect of the daucosterol

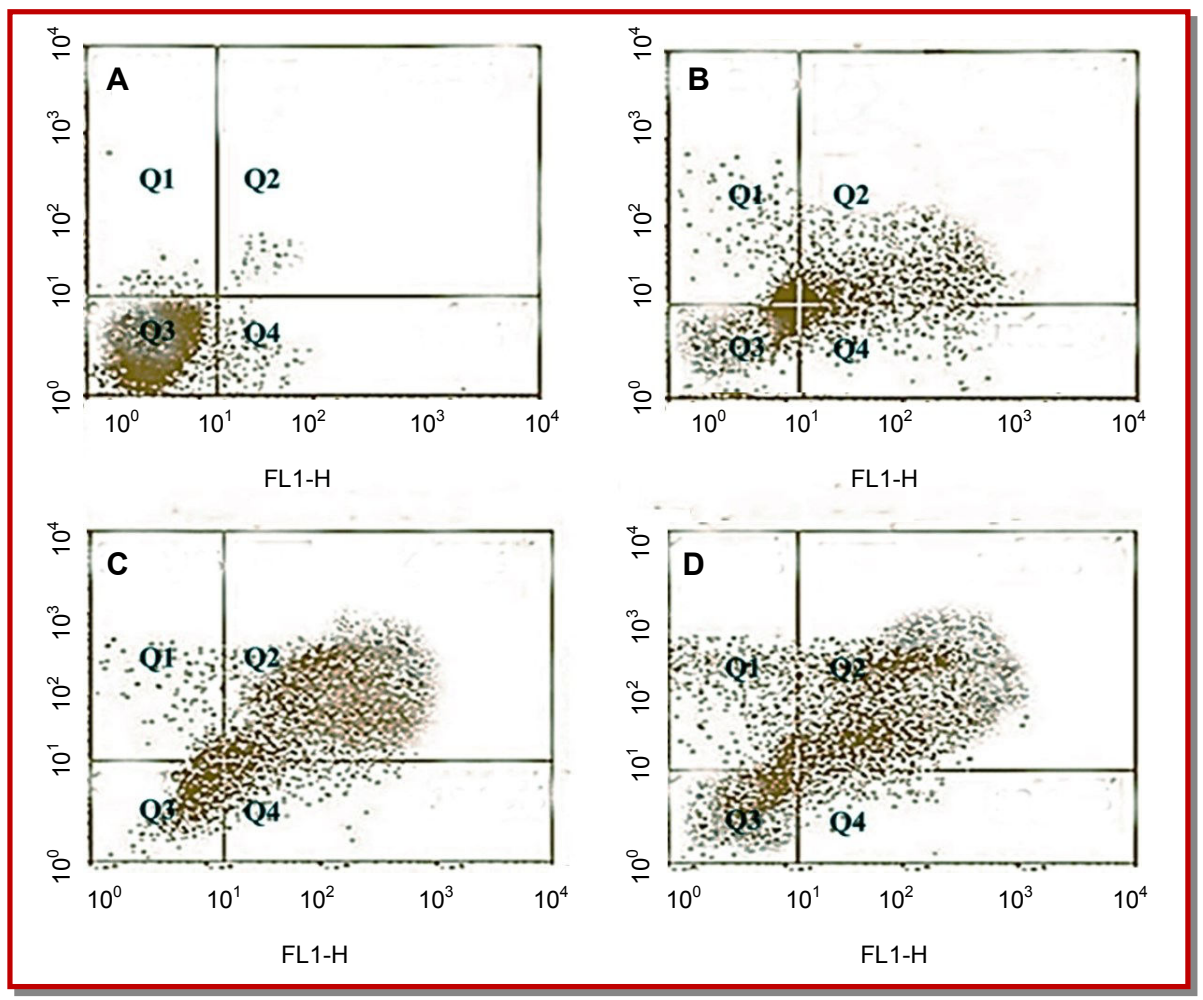

Figure 5: Evaluation of the apoptosis induction by daucosterol in HCT-116 human colon cancer cells using flow cytometry. The cells were treated with 0 (A-0.5\% DMSO-PBS), 5 (B), 50 (C) and $100 \mu \mathrm{M}$ (D) dose of daucosterol and then incubated for 48 hours stained with annexin V-FITC and then analyzed by flow cytometry. Data summary and analysis of the proportion of HCT-116 cells in different periods was according to the results of flow cytometric analysis 


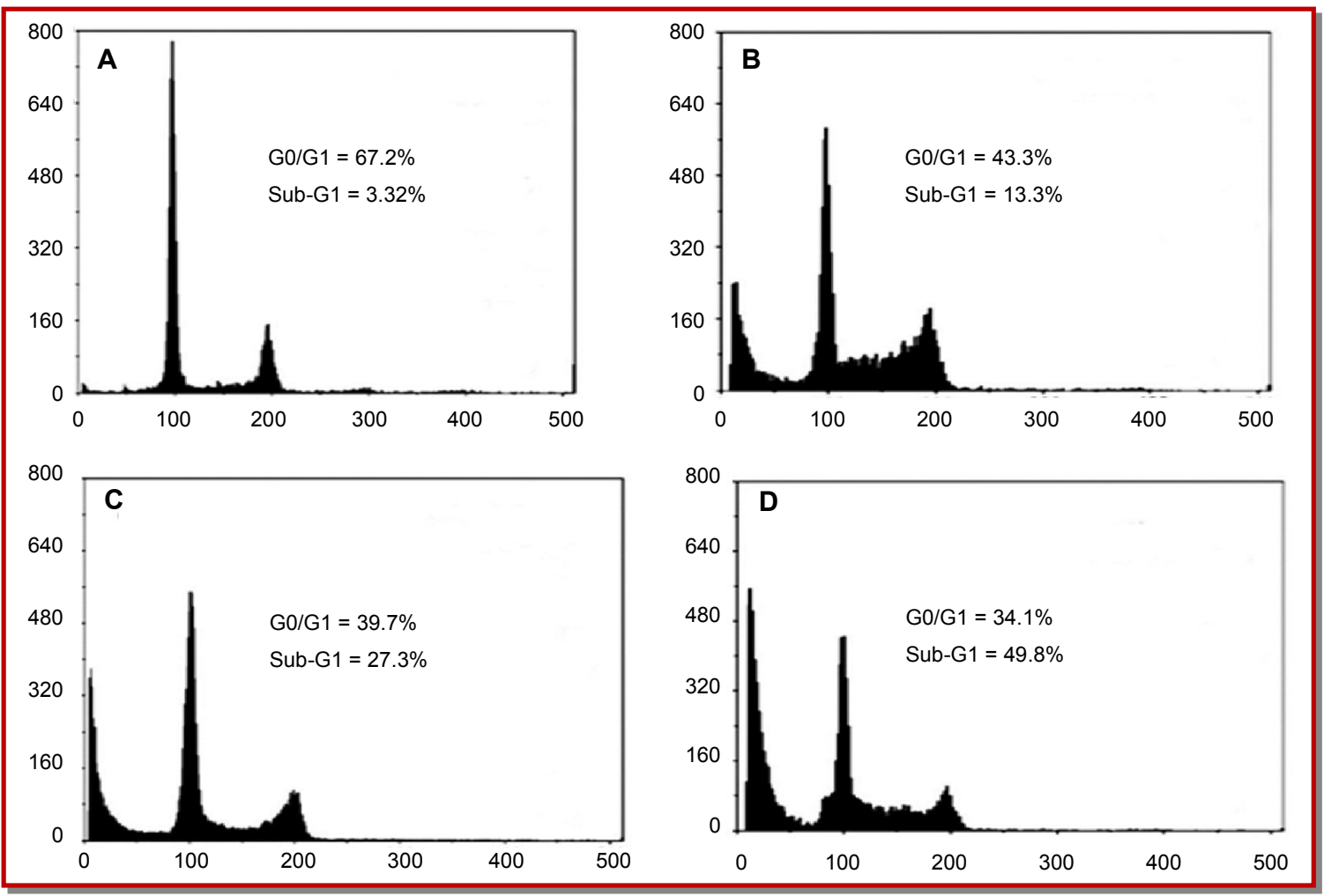

Figure 6: Effect of daucosterol on the cell cycle phase distribution in HCT-116 human colon carcinoma cells. The cells were treated with 0 (A-0.5\% DMSO-PBS), 5 (B), 50 (C) and $100 \mu \mathrm{M}$ (D) dose of daucosterol and then incubated for 48 hours stained with propidium iodide and then analyzed by flow cytometry. The percentage of cells in sub-G1 phase continuously increased from $3.32 \%$ in control group to $12.4 \%, 28.3 \%$ and $47.6 \%$ in groups treated with 5,50 and $100 \mu \mathrm{M}$ dose of daucosterol respectively

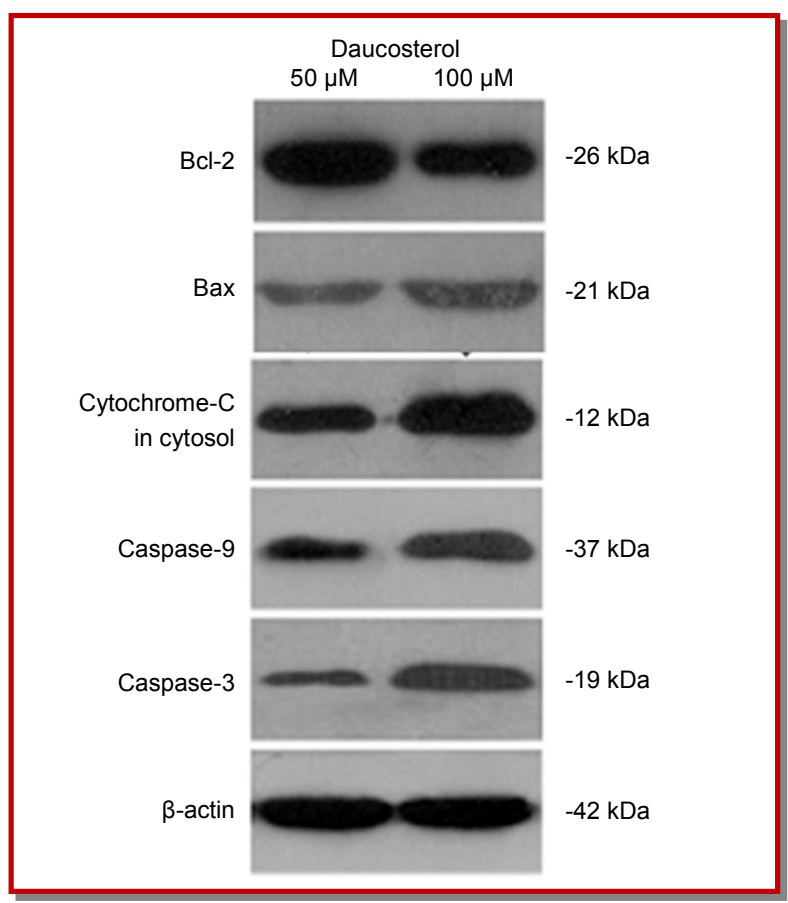

Figure 7: Western blot analysis of the various proteins associated with the apoptotic process causes HCT-116 cells to enter the sub-G1 phase of the cell cycle which is also called as the apoptotic phase. Western blot results revealed that the Bcl-2 expression levels were decreased while as the Bax, cytochrome c, caspase- 3 and caspase- 9 increased after treatment with 50 and $100 \mu \mathrm{M}$ concentrations of daucosterol.

It is now well established that there is a close relation between apoptosis process and the malignant phenoltype. There are enough evidences that various mutations in oncogenes deregulate the apoptosis process resulting in cancer initiation, its progression and finally its metastasis. Studies have shown that most of the anticancer agents induce apoptosis in cancer cells leading to their eradication (Lowe and Lin, 2000; RodriguezNieto and Zhivotovsky, 2006). A potent anti-cancer drug should either killer weaken tumor cells without leading to excessive injury to normal cells. This superlative state is possible by apoptotic induction in cancer cells. Numerous anticancer agents work principally to induce apoptosis in cancer cells and results in prevention of tumor progression (Miquel et al., 1996; Yoon et al., 1999; Ariazi et al., 1999; Sakagami et al., 1995). 


\section{Conclusion}

Daucosterol exhibits anti-cancer activity and induces apoptosis in HCT-116 human colon cancer cells. It has shown to repress the cell migration and cell invasion in these cells. Daucosterol also led to sub-G1 phase arrest along with modulating the expression levels of proteins that play a major role in apoptosis.

\section{Conflict of Interest}

The authors declare that there is no conflict of interest to reveal.

\section{References}

Ariazi EA, Satomi Y, Ellis MJ, Haag JD, Shi W, Sattler CA, Gould MN. Activation of the transforming growth factor beta signaling pathway and induction of cytostasis and apoptosis in mammary carcinomas treated with the anticancer agent perillyl alcohol. Cancer Res. 1999; 59: 191728.

de Gramont A, Figer A, Seymour M, Homerin M, Hmissi A, Cassidy J, Boni C, Cortes-Funes H, Cervantes A, Freyer G, Papamichael D, Le Bail N, Louvet C, Hendler D, de Braud F, Wilson C, Morvan F, Bonetti A. Leucovorin and fluorouracil with or without oxaliplatin as first-line treatment in advanced colorectal cancer. J Clin Oncol. 2000; 18: 2938-47.

Douillard JY, Siena S, Cassidy J, Tabernero J, Burkes R, Barugel M, Humblet Y, Bodoky G, Cunningham D, Jassem J, Rivera F, Kocákova I, Ruff P, Błasińska-Morawiec M, Šmakal M, Canon JL, Rother M, Oliner KS, Wolf M, Gansert J. Randomized phase III trial of panitmumab with infusional fluorouracil, leucovorin, and oxaliplatin (FOLFOX4) versus FOLFOX4 alone as first-line treatment in patients with previously untreated metastatic colorectal cancer: The PRIME study. J Clin Oncol. 2010; 28: 4697-705.

Ferlay J, Shin HR, Bray F, Forman D, Mathers C, Parkin DM.
Estimates of world wide burden of cancer in 2008: GLOBOCAN 2008. Int J Cancer. 2010; 127: 2893-917.

Folprecht G, Grothey A, Alberts S, Raab HR, Kohne CH. Neoadjuvant treatment of unresectable colorectal liver metastases: Correlation between tumour response and resection rates. Ann Oncol. 2005; 16: 1311-19.

Friedl P, Wolf K. Tumour-cell invasion and migration: Diversity and escape mechanisms. Nat Rev Cancer. 2003; 3: 362-74.

Lowe SW, Lin AW. Apoptosis in cancer. Carcinogenesis 2000; 21: 485-95.

Miquel K, Pradines A, Tercé F, Selmi S, Favre G. Farnesol and geranylgeraniol induce actin cytoskeleton disorganization and apoptosis in A549 lung adenocarcinoma cells. Biochem Biophys Res Commun. 1996; 225: 869-76.

Rodriguez-Nieto S, Zhivotovsky B. Role of alterations in the apoptotic machinery in sensitivity of cancer cells to treatment. Curr Pharm Des. 2006; 12: 4411-25.

Sakagami H1, Kuribayashi N, Iida M, Sakagami T, Takeda M, Fukuchi K, Gomi K, Ohata H, Momose K, Kawazoe Y. Induction of DNA fragmentation by tannin- and ligninrelated substances. Anticancer Res. 1995; 15: 2121-28.

Saltz LB, Clarke S, Díaz-Rubio E, Scheithauer W, Figer A, Wong R, Koski S, Lichinitser M, Yang TS, Rivera F, Couture F, Sirzén F, Cassidy J. Bevacizumab in combination with oxaliplatin-based chemotherapy as first-line therapy in metastatic colorectal cancer: A randomized phase III study. J Clin Oncol. 2008; 26: 2013-19.

Van Cutsem E, Oliveira J. Advanced colorectal cancer: ESMO clinical recommendations for diagnosis, treatment and follow-up. Ann Oncol. 2009; 20: 61-63.

Yamaguchi H, Wyckoff J, Condeelis J. Cell migration in tumors. Curr Opin Cell Biol. 2005; 17: 559-64.

Yoon Y, Kim YO, Lim NY, Jeon WK, Sung HJ. Shikonin, an ingredient of Lithospermum erythrorhizon induced apoptosis in HL60 human premyelocytic leukemia cell line. Planta Med. 1999; 65: 532-35.

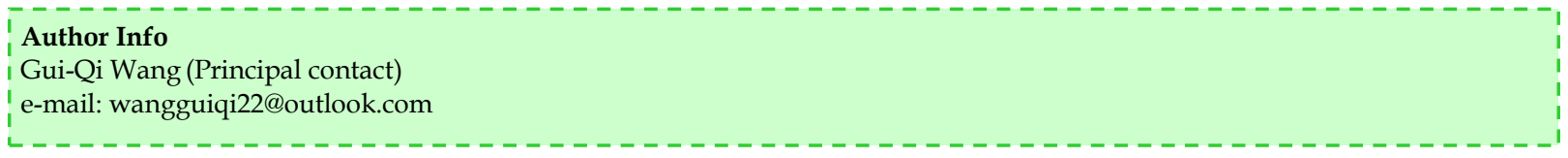




\section{Your feedback about this paper}

1. Number of times you have read this paper 0

2. Quality of paper

$\bigcirc$ Excellent $\bigcirc$ Good $\bigcirc$ Moderate $\bigcirc$ Not good

3. Your comments

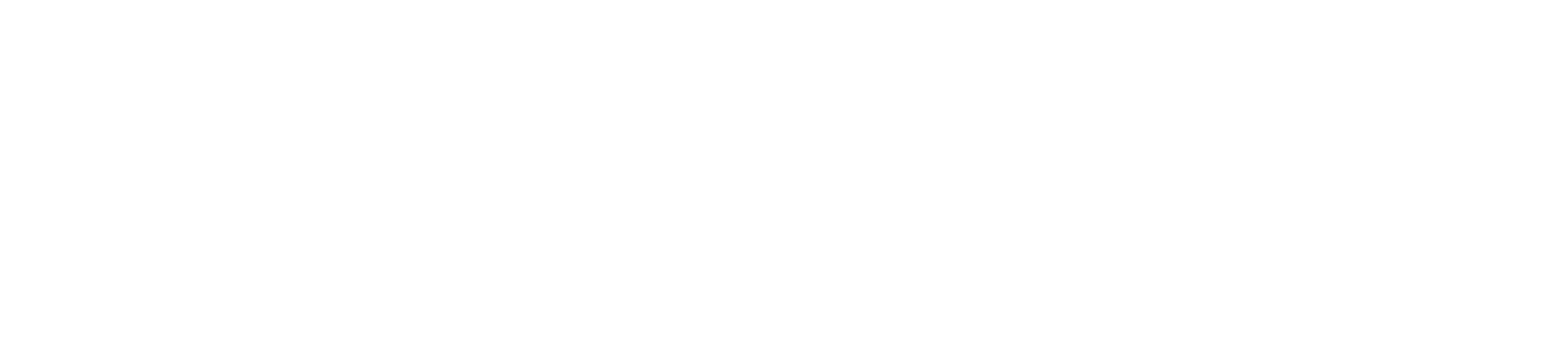

